\title{
Comportamento ingestivo e metabólico de bovinos de corte alimentados com rações contendo diferentes teores de torta de nabo forrageiro (Rhaphanus sativus) em substituição ao farelo de soja ${ }^{1}$
}

\section{Ingestive and metabolic behavior of beef cattle fed diets with different levels of turnip forage (Rhaphanus sativus) cake in replacement to soybean meal}

\author{
Valdecir de Souza Castro ${ }^{2}$; Leandro das Dores Ferreira da Silva ${ }^{3 *}$; \\ Ana Paula de Souza de Fortaleza ${ }^{3}$; Fernando Henrique Brussi Beran ${ }^{4}$; \\ Fernando Luiz Massaro Junior'; Edson de Azambuja Ribeiro ${ }^{3}$; \\ Marco Aurélio Alves de Freitas Barbosa ${ }^{3}$; Valter Harry Bumbieris Junior ${ }^{3}$; \\ Ivone Yurika Mizubuti³; Odimári Pricila Pires do Prado ${ }^{3}$
}

\section{Resumo}

O objetivo deste trabalho foi avaliar a substituição do farelo de soja pela torta de nabo forrageiro (Rhaphanus sativus) no concentrado, sobre o consumo de matéria seca, matéria orgânica, proteína bruta, extrato etéreo, fibra em detergente neutro e da fibra em detergente ácido, $\mathrm{pH}$ e nitrogênio amoniacal $\left(\mathrm{N}_{-} \mathrm{NH}_{3}\right)$ no líquido ruminal e uréia plasmática em bovinos de corte. As rações foram isoprotéicas $(6,5 \% \mathrm{~PB})$ e isoenergéticas $(50,0 \% \mathrm{NDT})$, sendo a silagem de cana-de-açúcar in natura usada como volumoso ( $85,5 \%$ da MS). Foram utilizados cinco bovinos machos, castrados, $1 / 2$ sangue SimentalNelore, com peso médio de $610 \mathrm{~kg}$ e 36 meses de idade, todos fistulados no rúmen. Os teores de substituição do farelo de soja pela torta de nabo forrageiro foram: 0 (controle), 25, 50,75 e $100 \%$, com base na representação protéica do farelo de soja na ração controle. Cada período experimental teve duração de 19 dias. O experimento foi conduzido em um delineamento experimental em quadrado latino $5 \times 5$, sendo 5 animais e 5 períodos. O potencial de consumo de MS em $\% \mathrm{PV}$ e em g/kg PV ${ }^{0,75}$ da torta de nabo forrageiro foi obtido com $27 \%$ de substituição na base protéica em relação ao farelo de soja, promovendo através desta, um consumo máximo de $0,217 \mathrm{~kg} / \mathrm{animal} / \mathrm{dia}$, não provocando alterações na dinâmica ruminal e no sangue.

Palavras-chave: Biodiesel, consumo, co-produto, nitrogênio amoniacal, nitrogênio ureico plasmático, $\mathrm{pH}$

\begin{abstract}
The objective of this study was to assess the effects of five substitution levels of soybean meal by turnip forage cake in the concentrate, on dry matter intake (DM), organic matter $(\mathrm{OM})$, crude protein $(\mathrm{CP})$, ether extract (EE), neutral detergent fiber (NDF) and acid detergent fiber (ADF), $\mathrm{pH}$ and ammonia nitrogen $\left(\mathrm{N}-\mathrm{NH}_{3}\right)$ in the rumen liquid and plasmatic urea nitrogen (PUN) in beef steer. The diets were
\end{abstract}

\footnotetext{
${ }^{1}$ Dissertação de mestrado do primeiro autor do Dept ${ }^{\circ}$ de Zootecnia., Pós-Graduação em Produção Animal, CCA, Universidade Estadual de Londrina de Londrina, UEL, Londrina

${ }^{2}$ Pesquisador, Montanapec, Londrina, PR. E-mail: val_montana@yahoo.com.br

${ }^{3}$ Profs. Drs. do Dept ${ }^{\mathrm{o}}$ de Zootecnia, UEL, Londrina, PR. E-mail: leandro@uel.br; anapaula_fortaleza@uel.br; elar@uel.br; maafbarbosa@uel.br; jrbumbieri@uel.br; mizubuti@uel.br; odimari@uel.br

${ }^{4}$ Discentes de Doutorado, de Pós-graduação em Ciência Animal, área de Produção Animal, UEL, Londrina, PR. E-mail: brussiberan@yahoo.com.br; nandomassar@hotmail.com

* Autor para correspondência
} 
isoprotein $(6.5 \% \mathrm{CP})$ and isoenergetic $(50.0 \% \mathrm{TDN})$, using in natura sugarcane silage as the only forage $(85,5 \% \mathrm{DM})$. Five castrated males were used, $1 / 2$ Simental $x$ Nelore cross, with average weight of $610 \mathrm{~kg}$ and 36 months old, all fistulated in the rumen. The different levels of replacement were: 0,25 , 50,75 and $100 \%$, based on CP responsible of soybean meal of ration. Each experimental period lasted 19 days. The experiment was carried out in a $5 \times 5$ latin square experimental design, with five animals and five periods. The potential of dry matter intake $\left(\% \mathrm{BW}\right.$ and $\left.\mathrm{g} / \mathrm{kg} \mathrm{BW}^{0,75}\right)$ of turnip forage cake forage was obtained with $27 \%$ of replacement in the protean basis in relation to soybean meal, promoting, a maximum intake of $0,217 \mathrm{~kg} / \mathrm{animal} / \mathrm{day}$, not proportionating alterations in the ruminal dynamic and in the blood.

Key words: Ammonia nitrogen, biodiesel, by-product, intake, plasmatic urea nitrogen, $\mathrm{pH}$

\section{Introdução}

O Brasil possui grandes quantidades de coderivados das agroindústrias com grande potencial de uso na alimentação de ruminantes, dentre eles os advindos da extração de óleo vegetal é um fato. As limitações para a transformação dos resíduos em coprodutos para alimentação animal estão ligadas à deficiência e/ou a desequilíbrios nas características nutricionais do resíduo e aos custos com a colheita, transporte e tratamentos quando necessário para melhoria de seu valor nutritivo (BURGI, 1992).

A utilização das tortas destas oleaginosas na alimentação animal tem despertado o interesse de vários produtores, que em certos casos fornecem este alimento aos animais mesmo sem saber informações básicas sobre limitação de consumo (NEIVA JUNIOR, 2007). Dentre as várias oleaginosas disponíveis no mercado, o nabo forrageiro (Rhaphanus sativus), planta da família Brassicaceae, é muito utilizada na adubação verde de inverno, rotação de culturas e recentemente na nutrição animal. A sua utilização era quase que exclusivamente como adubo verde por disponibilizar maior quantidade de matéria orgânica para o solo, com o intuito de aumentar a produtividade de culturas de inverno, como o milho e outra cultura em plantio direto.

Com a implantação do Programa Nacional de Produção de Biodiesel, a disponibilidade da torta de nabo forrageiro tornou-se uma realidade nos últimos anos. Portanto, o estudo de viabilidade deste co-produto na nutrição de bovinos se faz necessário, tendo como foco atender os anseios dos pecuaristas em ter uma fonte de proteína a baixo custo e contribuir com o possível destino de um produto da cadeia produtiva.

\section{Material e Métodos}

O presente estudo foi realizado na Unidade de Estudos de Ruminantes (UNER) da Fazenda Escola (FAZESC) e no Laboratório de Alimentos e Nutrição Animal (LANA) do Departamento de Zootecnia da Universidade Estadual de Londrina. O experimento foi realizado no período de outubro de 2006 a janeiro de 2007. Para tanto foram utilizados cinco bovinos machos $1 / 2$ Simental $1 / 2$ Nelore, evermifugados, castrados, fistulados no rúmen e portando cânula permanente, tendo como peso e idade média de $610 \mathrm{~kg}$ e 36 meses, respectivamente.

Os animais permaneceram durante todo $\mathrm{o}$ experimento em baias individuais cobertas (3 metros de comprimento X 1,10 metros largura) providas de bebedouro e comedouro. O fornecimento de água foi ad libitum e as rações diariamente às 8:00 e 17:00 horas, de tal forma a se obter $10 \%$ de sobras.

O experimento teve duração de 95 dias, sendo divido em 5 períodos de 19 dias, onde os 15 primeiros foram destinados à adaptação e os 4 dias finais correspondentes à coleta de amostras. Para a formulação das rações experimentais foi utilizado como volumoso a silagem de cana-de-açúcar e como concentrados o milho, farelo de soja, torta de nabo forrageiro e suplemento mineral (Tabela 1). 
As rações experimentais foram formuladas de forma isoprotéicas e isoenergéticas, de acordo com as exigências nutricionais propostas pelo NRC (1996) para um ganho médio diário de $0,500 \mathrm{~kg} / \mathrm{dia}$ (Tabela 2).

Os níveis de substituição do farelo de soja por torta de nabo forrageiro utilizados nesta avaliação foram: $0,25,5075$ e $100 \%$. A substituição foi realizada em relação à percentagem da contribuição da proteína bruta do farelo de soja na dieta controle, ou seja, após a formulação da ração com o nível 0 de substituição, foi verificado a representação da proteína bruta proveniente do farelo de soja na fórmula, a partir deste valor que foram realizados os níveis de substituição.

Tabela 1. Valores nutricionais dos ingredientes utilizados nas rações experimentais(\% na matéria seca).

\begin{tabular}{lcccc}
\hline \multirow{2}{*}{\multicolumn{1}{c}{ Nutrientes }} & \multicolumn{4}{c}{ Ingredientes } \\
\cline { 2 - 4 } & SC & TNF & FS & MT \\
\hline Matéria Seca & 27,37 & 96,30 & 88,78 & 87,11 \\
Matéria Orgânica & 92,12 & 94,45 & 93,30 & 98,73 \\
Matéria Mineral & 7,88 & 5,55 & 6,70 & 1,27 \\
Proteína Bruta & 2,94 & 40,91 & 51,13 & 8,26 \\
Proteína Degradável no Rúmen & $1,66^{2}$ & $23,65^{3}$ & $44,26^{3}$ & $4,48^{3}$ \\
Extrato Etéreo & 0,56 & 17,93 & 2,82 & 3,61 \\
Fibra Bruta & 37,71 & 7,23 & 4,77 & 1,73 \\
Fibra em Detergente Neutro & 76,10 & 23,74 & 9,86 & 11,73 \\
Fibra em Detergente Ácido & 43,46 & 14,84 & 7,56 & 3,54 \\
Extrato Não Nitrogenado & 50,92 & 28,39 & 34,57 & 72,24 \\
Nutrientes Digestíveis Totais ${ }^{1}$ & 47,21 & 95,47 & 83,97 & 77,68 \\
\hline
\end{tabular}

$\mathrm{SC}=$ Silagem de Cana-de-açúcar; TNF = Torta de Nabo Forrageiro, FS=Farelo de Soja e MT = Milho Triturado.

${ }^{1}$ Formula proposta por Kearl (1982)

Silagem de Cana-de-açúcar: NDT $=-21,9391+(1,0538 \times \mathrm{PB})+(0,9738 \times \mathrm{ENN})+(3,0016 \times \mathrm{EE})+(0,4590 \times \mathrm{FB})$

Torta de Nabo Forrageiro e Farelo de Soja: NDT $=40,3217+(0,5398 \times \mathrm{PB})+(0,4448 \times \mathrm{ENN})+(1,4223 \times \mathrm{EE})-(0,7007 \times \mathrm{FB})$

Milho Triturado: NDT $=40,2625+(0,1969 \times \mathrm{PB})+(0,4028 \times \mathrm{ENN})+(1,903 \times \mathrm{EE})-(0,1379 \times \mathrm{FB})$

${ }^{2}$ Silva et al. (2005).

${ }^{3}$ Fortaleza (2007).

Fonte: Elaboração dos autores. 
Tabela 2. Formulação e valor nutricional das rações experimentais (\% na matéria seca).

\begin{tabular}{|c|c|c|c|c|c|}
\hline \multirow{2}{*}{ Alimentos } & \multicolumn{5}{|c|}{ Níveis de substituição } \\
\hline & $0 \%$ & $25 \%$ & $50 \%$ & $75 \%$ & $100 \%$ \\
\hline \multicolumn{6}{|c|}{ Formulação } \\
\hline Silagem de Cana-de-açúcar & 85,50 & 85,50 & 85,50 & 85,50 & 85,50 \\
\hline Farelo de Soja & 6,70 & 5,02 & 3,36 & 1,67 & - \\
\hline Torta de Nabo Forrageiro & - & 2,13 & 4,28 & 6,04 & 9,39 \\
\hline Milho Triturado & 5,94 & 5,49 & 5,00 & 4,93 & 3,25 \\
\hline Suplemento Mineral & 1,86 & 1,86 & 1,86 & 1,86 & 1,86 \\
\hline Total & 100,00 & 100,00 & 100,00 & 100,00 & 100,00 \\
\hline \multicolumn{6}{|c|}{ Valor Nutricional } \\
\hline Nutrientes Digestíveis Totais* & 50,60 & 50,88 & 51,16 & 51,36 & 51,86 \\
\hline Proteína Bruta & 6,50 & 6,46 & 6,43 & 6,26 & 6,63 \\
\hline Proteína Degradável no Rúmen & 4,65 & 4,39 & 4,15 & 3,81 & 3,79 \\
\hline Extrato Etéreo & 0,88 & 1,20 & 1,52 & 1,79 & 2,28 \\
\hline Fibra em Detergente Neutro & 66,42 & 66,71 & 67,00 & 67,24 & 67,68 \\
\hline Fibra em Detergente Ácido & 37,88 & 38,05 & 38,22 & 38,36 & 38,67 \\
\hline
\end{tabular}

* Formula proposta por Kearl (1982):

Silagem de Cana-de-açúcar: NDT $=-21,9391+(1,0538 \times \mathrm{PB})+(0,9738 \times \mathrm{ENN})+(3,0016 \times \mathrm{EE})+(0,4590 \times \mathrm{FB})$

Torta de Nabo Forrageiro e Farelo de Soja: NDT $=40,3217+(0,5398 \times$ PB $)+(0,4448 \times$ ENN $)+(1,4223 \times$ EE $)-(0,7007 \times$ FB $)$ Milho Triturado: NDT $=40,2625+(0,1969 \times \mathrm{PB})+(0,4028 \times \mathrm{ENN})+(1,903 \times \mathrm{EE})-(0,1379 \times \mathrm{FB})$.

Fonte: Elaboração dos autores.

Para a realização do cálculo de consumo expresso em $\mathrm{kg} / \mathrm{dia}$, \% Peso Vivo e g/kg Peso Vivo $^{0,75}$, amostras de sobras e fornecido foram coletadas nos últimos quatro dias de cada período $\left(16^{\circ}, 17^{\circ}, 18^{\circ}\right.$ e $\left.19^{\circ} \mathrm{dia}\right)$. Após a colheita as amostras foram pré-secas e posteriormente encaminhadas para a determinação de matéria seca (MS), matéria orgânica $(\mathrm{MO})$, proteína bruta $(\mathrm{PB})$, extrato etéreo (EE), fibra em detergente neutro (FDN) e da fibra em detergente ácido (FDA) segundo Silva e Queiroz (2002). A pesagem dos animais foi realizada antes de começar o experimento e sempre no último dia de cada período, para a realização do cálculo de consumo em relação ao peso vivo e peso metabólico.

Foram colhidos $50 \mathrm{~mL}$ de líquido ruminal através da cânula ruminal de cada animal no $19^{\circ}$ dia de cada período com intervalo de duas horas entre cada colheita. Os horários de colheita obedeceram ao fornecimento da ração, sendo considerado o tempo zero, correspondente a coleta antecedente a alimentação dos animais, e 2, 4, 6 e 8 horas após o fornecimento da ração ela manhã.
As amostras de líquido ruminal foram coletadas em quatro pontos diferentes do rúmen, e depois filtradas para posterior leitura do $\mathrm{pH}$ e determinação do $\mathrm{N}_{-} \mathrm{NH}_{3}$. $\mathrm{O} \mathrm{pH}$ foi determinado imediatamente após a filtragem do líquido com o auxílio de um potenciômetro digital Tecnal ${ }^{\circledR}$ modelo TEC 3MP .

Uma alíquota de $50 \mathrm{~mL}$ de cada amostra de líquido ruminal foi acidificada com a adição de 1 $\mathrm{mL}$ de ácido sulfúrico $1: 1$, condicionadas em frascos plásticos e congeladas a $-20{ }^{\circ} \mathrm{C}$, para posteriores determinações dos teores de $\mathrm{N}-\mathrm{NH}_{3}$.

Após descongelamento das amostras, as concentrações de $\mathrm{N}^{-\mathrm{NH}_{3}}$ foram determinadas pela destilação de $2 \mathrm{~mL}$ de cada amostra com adição de $5 \mathrm{~mL}$ de $\mathrm{KOH} 2 \mathrm{~N}$ em aparelho tipo Kjedhal. O destilado foi recebido em $10 \mathrm{~mL}$ de $\mathrm{H}_{3} \mathrm{BO}_{3} 2 \%$ até um volume final de $50 \mathrm{~mL}$, seguido pela titulação com HCL 0,005 N, segundo a técnica de Fenner (1965) adaptada por Vieira (1980).

As amostras de sangue foram colhidas por punção da veia jugular no $19^{\circ}$ dia de cada período 
com intervalo de duas horas entre cada coleta. Os horários de colheita obedeceram ao fornecimento da ração, sendo considerado o tempo zero, correspondente a coleta antecedente a alimentação dos animais, e 2, 4, 6 e 8 horas após o fornecimento da ração ela manhã. O sangue foi coletado em tubos 13 X $17 \mathrm{~mm}$ com heparina sódica, em seguida os tubos foram invertido suavemente a $180^{\circ}$ cinco vezes para a mistura com o anticoagulante. Após a coleta precedeu-se a centrifugação das amostras à 4000 RPM por 10 minutos para a obtenção do plasma. Para a determinação do Nitrogênio Uréico Plasmático (NUP), utilizou-se o método enzimático colorimétrico com o kit Labtest ${ }^{\circledR}$.

O experimento foi conduzido em um delineamento experimental em quadrado latino 5 x 5, com cinco animais, cinco períodos e cinco tratamentos. Para os parâmetros de consumo de componentes químicos avaliados foi utilizado modelo matemático:

$$
\mathrm{Y}_{\mathrm{ijk}}=\mu+\mathrm{A}_{\mathrm{i}}+\mathrm{P}_{\mathrm{j}}+\mathrm{T}_{\mathrm{k}}+\mathrm{E}_{\mathrm{ijk}}
$$

Onde: $\mathrm{A}=$ Animal, $\mathrm{P}=$ Período, $\mathrm{T}=$ Tratamento e $\mathrm{E}=$ Erro experimental.

Para as parcelas subdivididas $\left(\mathrm{pH}, \mathrm{N}-\mathrm{NH}_{3}\right.$ e NUP) o modelo matemático utilizado foi:

$\mathrm{Y}_{\mathrm{ijkl}}=\mu+\mathrm{A}_{\mathrm{i}}+\mathrm{P}_{\mathrm{j}}+\mathrm{T}_{\mathrm{k}}+\left(\mathrm{A}_{\mathrm{i}} \mathrm{x}_{\mathrm{j}} \mathrm{xT}_{\mathrm{k}}\right)+\mathrm{H}_{1}+\left(\mathrm{T}_{\mathrm{k}}\right.$ $\left.\mathrm{x} \mathrm{H}_{\mathrm{l}}\right)+\mathrm{E}_{\mathrm{ijkl}}$

Onde: $\mathrm{A}=$ Animal, $\mathrm{P}=$ Período, $\mathrm{T}=$ Tratamento $\mathrm{H}=$ Tempo, $\mathrm{A}_{\mathrm{i}} \times \mathrm{P}_{\mathrm{j}} \times \mathrm{T}_{\mathrm{k}}=$ Erro experimental parcela, $\mathrm{T}_{\mathrm{k}} \times \mathrm{H}_{1}=$ Interação Tratamento $\mathrm{x}$ Tempo e $\mathrm{E}=$ Erro experimental - sub parcela.

Adotou-se para análise variância e regressão os procedimentos GLM e REG, respectivamente, todos estes pertencentes ao programa estatístico SAS (2001). As diferenças entre as médias para as diversas variáveis avaliadas foram verificadas através do Teste de Tukey, considerando-se 5\% como nível de significância.

\section{Resultados e Discussão}

Os dados de consumo em $\mathrm{kg} /$ dia, \%Peso Vivo e $\mathrm{g} / \mathrm{kg} \mathrm{PV}^{0,75}$ de matéria seca (MS), matéria orgânica $(\mathrm{MO})$, proteína bruta $(\mathrm{PB})$, extrato etéreo $(\mathrm{EE})$, fibra em detergente neutro (FDN) e da fibra em detergente ácido (FDA), estão contidos na Tabela 3.

Os consumos de MS, MO, FDN e FDA em kg/dia não apresentaram diferença significativa em função dos níveis estudados. Entretanto, foram verificados os maiores valores de consumo de $\mathrm{PB} \mathrm{kg} /$ dia para os níveis até $50 \%$ de substituição do farelo de soja (FS) por torta de nabo forrageiro (TNF). Analisando a equação de regressão do consumo de $\mathrm{PB} \mathrm{kg} / \mathrm{dia}$ é possível observar que ocorreu efeito quadrático, resultando em $31,11 \%$ de substituição como o ponto máximo de consumo deste componente nutritivo, valor este que representa um consumo de $1,25 \mathrm{~kg}$ de $\mathrm{PB} /$ dia.

O consumo de $\mathrm{EE}$ em $\mathrm{kg} / \mathrm{dia}$ foi afetado significativamente em função da presença da TNF na dieta dos animais, onde os níveis entre 50 e $75 \%$ de substituição proporcionaram os maiores valores. Fato este confirmado pelo comportamento da equação de regressão quadrática verificada para este componente nutritivo, onde TNF proporcionou máximo de ingestão de EE a 57,99\% de substituição, ou seja, 0,27 kg de EE/dia. Este comportamento é justificado pela concentração deste componente ser maior à medida que foi realizada a substituição do FS pela TNF nas rações experimentais Tabela 2.

Ao observar os valores de consumo dos diferentes componentes em \% Peso Vivo (\%PV) (Tabela 3) é possível observar que, dentre os níveis estudados, os maiores valores de consumo de MS e MO foram encontrados para a substituição de $25 \%$ da TNF por FS, resultando em 1,58 e 1,19\% PV, respectivamente. Ao mesmo tempo, correlacionando estes valores com o comportamento quadrático da equação de regressão observada para estes componentes, constatou-se que 26,97 e $33,73 \%$ de substituição promoveram o potencial de consumo de MS e MO, repercutindo, desta forma, o consumo máximo de 1,58 e $1,23 \% \mathrm{PV}$, respectivamente, quando se utiliza estes níveis de substituição. 


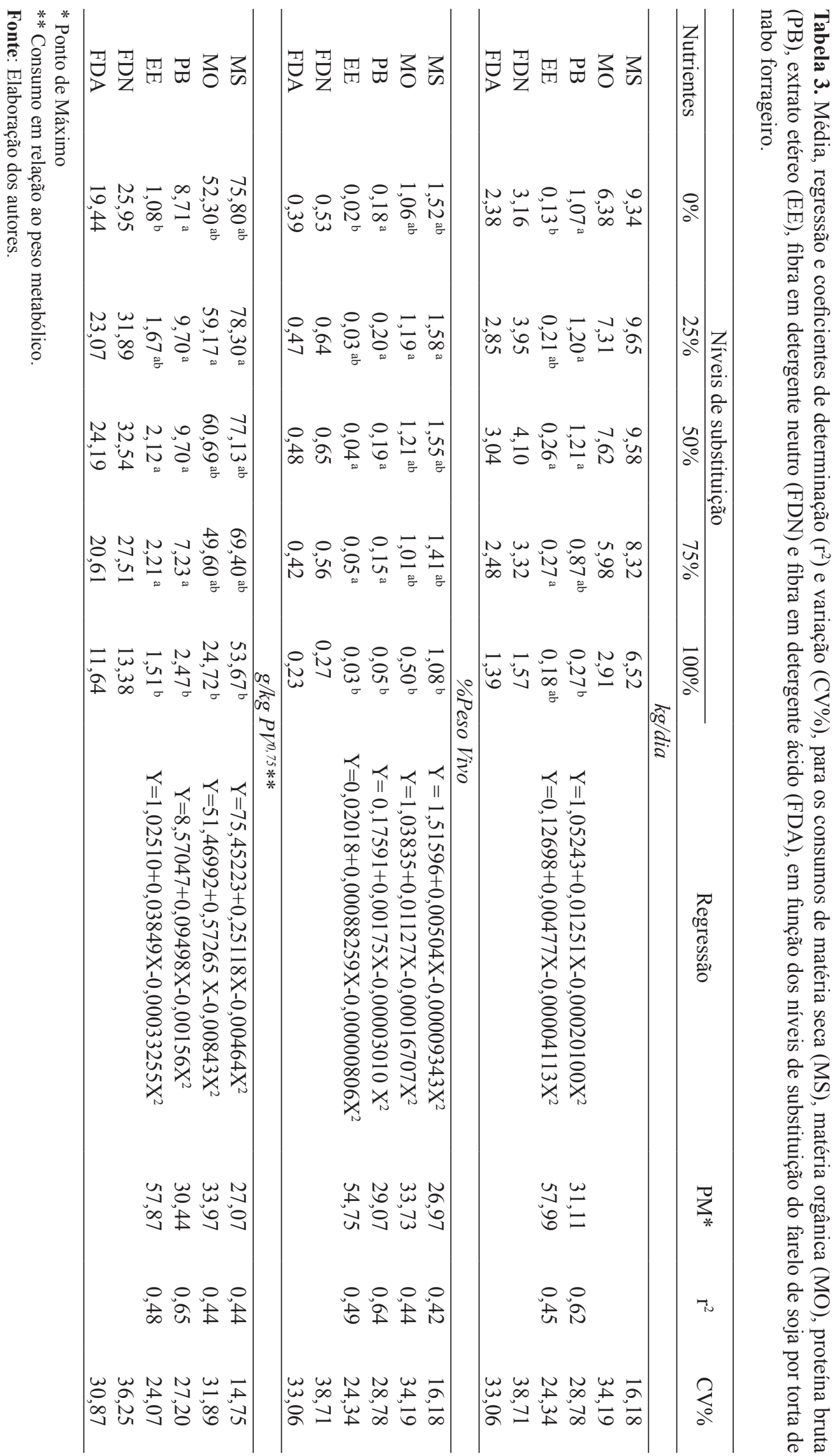


Avaliando o potencial de consumo de MS de $1,58 \%$ PV que representa $26,97 \%$ de substituição do FS por TNF, este nível promoveu uma ingestão de $0,217 \mathrm{~kg}$ de TNF. Este valor reflete uma alternativa de utilizar a TNF em suplementos pelo baixo consumo, destinados a animais mantidos em sistema a pasto ou até mesmo como regulador de consumo de suplementos altamente palatáveis.

No intuito de verificar a característica de limitação de consumo da torta de nabo forrageiro na nutrição de bovinos, Barbero et al. (2008) ao avaliarem o consumo de MS e o ganho médio diário (GPDM) de novilhas mantidas em sistema de lotação rotacionada, recebendo três diferentes tipos de suplementos, verificaram o consumo e GPDM de $1,06 \mathrm{~kg}$ de $\mathrm{MS} /$ dia e $0,400 \mathrm{~kg} /$ dia, respectivamente, para o suplemento que possuía somente TNF como fonte exclusiva de proteína. Valores estes muito abaixo ao observado para o suplemento com farelo de soja $(2,22 \mathrm{~kg}$ de MS/dia e $0,810 \mathrm{~kg} / \mathrm{dia})$ e com caroço de algodão $(2,27 \mathrm{~kg}$ de MS/dia e $0,760 \mathrm{~kg} /$ dia). Com base no consumo e no GPDM obtidos com a utilização do suplemento com TNF, é possível verificar que o mesmo se apresentou como limitador de consumo, repercutindo desta forma em um baixo desempenho dos animais.

Mello et al. (2008) avaliando o efeito da inclusão de farelo de nabo forrageiro com base na matéria seca de $0 ; 7,5$ e $15 \%$ na dieta de bovinos Nelore, com peso e idade de $285 \mathrm{~kg}$ e 14 meses, respectivamente, mantidos em lotação rotacionada em capim Brachiaria Brizantha cv. Marandu, recebendo 600 gramas/dia de suplemento com $35 \% \mathrm{~PB}$, observaram um ganho de peso de 0,525;0,613 e 0,463 kg/ dia, para os níveis utilizados, respectivamente. Avaliando este trabalho é possível observar que o consumo de 90 gramas/cabeça/dia de farelo de nabo forrageiro diminuiu o consumo do suplemento e conseqüentemente o desempenho dos animais.

$\mathrm{O}$ consumo de $\mathrm{PB}$ em \%PV foi influenciado pela presença da TNF na dieta dos animais, fato este constatado pelo maior consumo ter ocorrido utilizando até $75 \%$ de substituição. Entretanto, o potencial de consumo deste componente foi verificado com $29,07 \%$ substituição, proporcionando, desta forma, consumo de 0,20 \%PV. Para o consumo de EE, a maior ingestão deste composto químico é obtida com $54,75 \%$ de substituição, o que representa na dieta $1,57 \%$ na MS, número este 3,16 vezes menor ao limite de 5\% para gado de corte recomendado pelo NRC (1996). Para os consumos em \%PV de FDN e FDA não foram observadas diferenças significativas entre os níveis analisados.

Segundo Coelho da Silva e Leão (1979) a exigência energética de mantença é o metabolismo do jejum corrigido por um fator de eficiência de utilização de energia alimentar para mantença e acrescido de uma quantidade adicional de energia para o trabalho muscular. Desta forma, o metabolismo do jejum é expresso em calorias por unidade de peso metabólico $\left(\mathrm{kcal} / \mathrm{kg} \mathrm{PV}^{0,75}\right)$. Ela varia com a idade, tamanho e espécie. Todavia, um valor médio de $70 \mathrm{Kcal} / \mathrm{kg}^{0,75}$ pode ser utilizado para bovinos. Portanto, na avaliação de dietas para bovinos, o consumo de nutrientes em relação ao peso metabólico $\left(\mathrm{g} / \mathrm{kg} \mathrm{PV}^{0,75}\right)$ é uma forma de avaliar o comportamento ingestivo de bovinos levando em consideração o metabolismo basal.

Mertens (1994) destaca que a base para expressar consumo não é a mesma para os mecanismos físicos e fisiológicos de controle. Para rações de baixa qualidade, em que ingestão é limitada pelo "enchimento" do rúmen, o ideal é expressá-lo em \% $\mathrm{PV}$, por se encontrar mais relacionado ao tamanho e à capacidade do trato digestivo. Quando o consumo é limitado pela demanda fisiológica de energia, a melhor forma de expressá-lo é com base no peso metabólico.

Os dados encontrados para o consumo em g/ $\mathrm{kg} \mathrm{PV}^{0,75}$ dos componentes nutritivos avaliados neste estudo, tiveram o mesmo comportamento de significância dos dados relacionados em \% $\mathrm{PV}$, onde foram encontrados os maiores consumos de 
MS, MO, PB e EE de 27,07, 33,97, 30,44 e 57,87 $\mathrm{g} / \mathrm{kg} \mathrm{PV} \mathrm{PV}^{0,75}$, respectivamente. Não houve efeito significativo entre os teores de substituição do farelo de soja por torta de nabo forrageiro para os consumos expressos em nas diferentes formas de expressão (kg/dia, \%PVe em g/kg PV $\left.{ }^{0,75}\right)$ de FDN e FDA.

De uma maneira geral, avaliando-se os diferentes parâmetros de ingestão dos componentes químicos determinados neste estudo, pode-se afirmar que o óleo da torta de nabo forrageiro, fatores antinutricionais e sua palatabilidade foram os fatores principais de redução no consumo daqueles componentes nutritivos estudados nos níveis acima de $27 \%$ de substituição do FS por TNF. Berchielli, Pires, Oliveira (2006) relataram que certos ácidos graxos, especialmente os poliinsaturados, são tóxicos aos microrganismos ruminais, sendo as bactérias Gran $(+)$, metanogênicos e protozoários, os mais suscetíveis.

O fato dos ácidos graxos poliinsaturados estarem na forma líquida à temperatura ruminal (38,5 a $39,5^{\circ} \mathrm{C}$ ) contribuiu para o aumento de sua superfície de contato, facilitando desta forma a formação de uma capa protetora que impede a adesão das bactérias ao substrato ruminal a ser fermentado, prejudicando de forma considerável a fermentabilidade ruminal realizada por elas. Portanto, a grande quantidade de ácidos graxos poliinsaturados observados por Ferreira, Santos e Souza (2008) presentes no óleo da torta de nabo forrageiro (88\%), evidência esta afirmação.

Dentre os fatores que afetam a redução do $\mathrm{pH}$ do líquido ruminal, o consumo dos nutrientes, relação volumoso:concentrado e os tipos de ingredientes utilizados, são notoriamente os mais significativos para a variação deste parâmetro em função do tempo após a alimentação dos animais. Neste sentido, a única diferença significativa foi verificada para o tempo 6 , onde o nível de substituição de $100 \%$ foi o que apresentou maior valor (Tabela 4).

Independente do nível de substituição utilizado nesta avaliação, a relação volumoso:concentrado de 85,50:14,50 foi capaz de manter o $\mathrm{pH}$ do liquido ruminal, em função dos tempos de coletas analisados, dentro da faixa de 6 e 7, considerada por Coelho da Silva e Leão (1979) como sendo a ideal e também próxima de 6,5 onde ocorre, segundo estes autores, a máxima atividade dos microrganismos ruminais.

Apesar do valor de $\mathrm{pH}$ de 6,81, encontrado para o tempo 6 do nível de $100 \%$ de substituição, ter sido maior significativamente em comparação aos demais níveis, os valores deste parâmetro para os demais tempos para este mesmo nível de substituição, também foram maiores numericamente quando comparado aos demais tratamentos. Fato este ocorrido em detrimento da redução do consumo dos nutrientes, quando se utilizou a TNF como única fonte protéica na dieta dos animais, conforme dados da Tabela 3.

Analisando o $\mathrm{pH}$ do líquido ruminal possível observar que os níveis com até $75 \%$ de substituição de FS por TNF, proporcionaram valores próximos a 6,5. Neste sentido, Hoover (1986) revelou que a redução da síntese bacteriana e na digestibilidade ruminal da FDN, acontece quando o $\mathrm{pH}$ no liquido ruminal for inferior a 6,2. Portanto, sob o aspecto de dinâmica ruminal, proporcionado pelo consumo das rações com os níveis de até $75 \%$ de substituição de FS por TNF, provavelmente estes efeitos não devem ter ocorridos.

Não foi verificada neste estudo a interação significativa entre as variáveis tratamento e tempo, entretanto avaliando o comportamento cúbico da equação de regressão para a variável tratamento, é possível observar que o ponto máximo encontrado na curva foi de $100 \%$ e como ponto mínimo o nível de $0 \%$ de substituição. Estes níveis, correspondem aos valores de $\mathrm{pH}$ de 6,85 e 6,49, respectivamente, estando nesta forma, dentro da faixa ideal de 6 a 7. Da mesma forma, analisando o comportamento quadrático da variável tempo, foi obtido como ponto mínimo e máximo, os tempos de 4,58 e 0 , correspondendo, aos valores de $\mathrm{pH}$ de 6,55 e 6,76, respectivamente. 


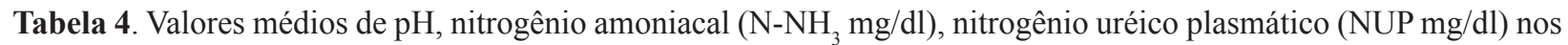
animais antes (0 horas) e após o fornecimento das rações (2, 4, 6 e 8 horas), equação de regressão e coeficientes de variação $(\mathrm{CV} \%)$ e determinação $\left(\mathrm{r}^{2}\right)$.

\begin{tabular}{|c|c|c|c|c|c|c|c|}
\hline \multirow{2}{*}{$\begin{array}{l}\text { Tempo } \\
\text { (horas) }\end{array}$} & \multicolumn{5}{|c|}{ Níveis de substituição do farelo de soja por torta de nabo forrageiro } & \multirow{2}{*}{ Média } & \multirow{2}{*}{$\mathrm{CV} \%$} \\
\hline & $0 \%$ & $25 \%$ & $50 \%$ & $75 \%$ & $100 \%$ & & \\
\hline \multicolumn{8}{|c|}{$p H$} \\
\hline 0 & 6,69 & 6,83 & 6,72 & 6,65 & 6,99 & 6,78 & 3,14 \\
\hline 2 & 6,46 & 6,63 & 6,62 & 6,52 & 6,77 & 6,60 & 3,59 \\
\hline 4 & 6,39 & 6,50 & 6,62 & 6,50 & 6,81 & 6,56 & 3,50 \\
\hline 6 & $6,40^{\mathrm{b}}$ & $6,53^{\mathrm{ab}}$ & $6,633^{a b}$ & $6,56^{\mathrm{ab}}$ & $6,81^{\mathrm{a}}$ & 6,59 & 3,11 \\
\hline 8 & 6,53 & 6,60 & 6,69 & 6,62 & 6,89 & 6,67 & 3,70 \\
\hline Média & 6,49 & 6,62 & 6,66 & 6,57 & 6,85 & & \\
\hline Variável & \multicolumn{4}{|c|}{ Regressão } & PMáx. & Pmín. & $\mathrm{R}^{2}$ \\
\hline Tratamento & \multicolumn{4}{|c|}{$Y=6,48551+0,01355 X-0,00034487 X^{2}+0,00000246 X^{3}$} & 100 & 0 & 0,11 \\
\hline Tempo & \multicolumn{4}{|c|}{$\mathrm{Y}=6,76454-0,09278 \mathrm{X}+0,01016 \mathrm{X}^{2}$} & 0 & 4,58 & 0,04 \\
\hline \multicolumn{8}{|c|}{$\mathrm{N}-\mathrm{NH}_{3} \mathrm{mg} / \mathrm{dl}$} \\
\hline 0 & 6,79 ab & $8,96^{\mathrm{a}}$ & $6,16^{\mathrm{ab}}$ & $6,30^{\mathrm{ab}}$ & $4,97^{\mathrm{b}}$ & 6,64 & 21,21 \\
\hline 2 & $6,44^{\mathrm{b}}$ & $8,54^{\mathrm{a}}$ & $6,02^{\mathrm{b}}$ & $5,88^{\mathrm{b}}$ & $4,41^{b}$ & 6,26 & 16,23 \\
\hline 4 & $4,76^{\mathrm{b}}$ & $7,91^{\mathrm{a}}$ & 6,04 ab & $5,53 \mathrm{ab}$ & $4,06^{\mathrm{b}}$ & 5,66 & 22,00 \\
\hline 6 & $3,85^{\mathrm{b}}$ & $6,30^{\mathrm{a}}$ & 5,67 ab & 4,34 ab & $3,71^{\mathrm{b}}$ & 4,77 & 22,12 \\
\hline 8 & 3,57 & 5,60 & 4,48 & 4,62 & 3,71 & 4,40 & 22,99 \\
\hline Média & 5,08 & 7,46 & 5,67 & 5,33 & 4,17 & & \\
\hline Variável & \multicolumn{4}{|c|}{ Regressão } & PMáx. & PMín. & $r^{2}$ \\
\hline Tratamento & \multicolumn{4}{|c|}{$Y=5,195+0,14445 X-0,00332 X^{2}+0,00001785 X^{3}$} & $28 \%$ & $97 \%$ & 0,23 \\
\hline Tempo & \multicolumn{4}{|c|}{$Y=6,7368-0,2982 X$} & 0 & 100 & 0,17 \\
\hline \multicolumn{8}{|c|}{$N U P m g / d l$} \\
\hline 0 & 11,24 & 13,41 & 11,21 & 10,35 & 13,33 & 11,91 & 42,71 \\
\hline 2 & $10,32^{a b}$ & $17,20^{\text {a }}$ & $7,65^{\mathrm{b}}$ & 11,17 ab & $8,39^{b}$ & 10,95 & 31,56 \\
\hline 4 & 14,58 & 15,41 & 12,90 & 13,44 & 7,17 & 12,70 & 54,08 \\
\hline 6 & $13,92^{b}$ & $21,19^{a}$ & $14,62^{b}$ & $13,88^{\mathrm{b}}$ & $11,59^{\mathrm{b}}$ & 15,04 & 12,62 \\
\hline 8 & $13,90^{\mathrm{b}}$ & $19,06^{\mathrm{a}}$ & $13,42^{b}$ & $11,87^{\mathrm{b}}$ & $12,36^{\mathrm{b}}$ & 14,12 & 13,99 \\
\hline Média & 12,79 & 17,25 & 11,96 & 12,14 & 10,57 & & \\
\hline Variável & \multicolumn{4}{|c|}{ Regressão } & PMáx. & PMín. & $r^{2}$ \\
\hline Tratamento & \multicolumn{4}{|c|}{$Y=14,85456-0,03824 X$} & 0 & 100 & 0,03 \\
\hline Tempo & \multicolumn{4}{|c|}{$\mathrm{Y}=11,24$} & & & \\
\hline
\end{tabular}

a,b: Médias seguidas de letras diferentes, em linha, diferem estatisticamente pelo Teste de Tukey $(\mathrm{P}<0,05)$.

Fonte: Elaboração dos autores.

Fazendo um paralelo com a curva de regressão da viável juntamente com o potencial de consumo de MS em \%PV e em g/kg PV ${ }^{0,75}$ obtidos com $27 \%$ de substituição de FS por TNF (Tabela 3), é possível verificar que o valor de $\mathrm{pH}$ proporcionado por esta inclusão é de 6,65 , ou seja, dentro da faixa de ideal de 6 a 7 . Portanto, o potencial de consumo da substituição de FS por TNF ao nível de $27 \%$, promove a produção de ácidos orgânicos no rúmen dentro da normalidade, em decorrência do valor de pH obtido a este nível.

O Sistema Cornell (CNCPS), divide os microrganismos ruminais em dois grupos, os que fermentam carboidratos não fibrosos (CNF) e 
aqueles que fermentam carboidratos fibrosos (CF). Isso é importante devido a utilização do $\mathrm{N}$ presente no rúmen, já que as bactérias que fermentam apenas a parede celular usam somente a amônia como fonte de $\mathrm{N}$ para sua síntese. No entanto, as bactérias fermentadoras de CNF utilizam peptídeos, ou aminoácidos, ou amônia como fonte de $\mathrm{N}$ (RUSSELL et al., 1992).

A concentração de $\mathrm{N}^{-\mathrm{NH}_{3}}$ no líquido ruminal obtidas neste estudo, de maneira geral foi influenciada pelos níveis de torta de nabo forrageiro utilizados nas rações experimentais. Sabe-se que a quantidade de $\mathrm{N}_{-} \mathrm{NH}_{3}$ no líquido ruminal está diretamente relacionada com o perfil de degradação da proteína dietética e a disponibilidade de energia para o crescimento microbiano (COELHO DA SILVA, LEÃO 1979).

Antes da alimentação dos animais, os teores $0,25,50$ e $75 \%$ de substituição, apresentaram os maiores valores de $\mathrm{N}_{-} \mathrm{NH}_{3}$. Entretanto, após 2, 4 e 6 horas após o fornecimento da dieta aos animais, a substituição de $25 \%$ de FS por TNF, proporcionaram os maiores valores de $\mathrm{N}_{-} \mathrm{NH}_{3}$. Um das justificativas para tal fato, mesmo levando em consideração a redução da PDR desta ração quando comparado a ração isenta deste co-produto (Tabela 2), é o aumento do consumo de ração proporcionado por este nível de substituição (Tabela 3).

Alguns estudos "in vitro" sugerem que a concentração de $\mathrm{N}^{-\mathrm{NH}_{3}}$ para se obter a máxima síntese microbiana por unidade de substrato fermentável seja de aproximadamente 5 a $6 \mathrm{mg}$ $\mathrm{N}-\mathrm{NH}_{3} / \mathrm{dL}$ de fluido ruminal (SLYTER, SATTER, DINIUS, 1979), faixa esta encontrada neste estudo, perante os níveis avaliados, até $75 \%$ de substituição. Porém, se a dieta fornecer altos teores de energia é sugerido trabalhar com concentrações maiores de $\mathrm{N}_{-} \mathrm{NH}_{3}$, como Odle et al. (1987) citado por Gabarra (2001), que obtiveram valores máximos de fermentação ruminal em bovinos de leite quando o teor de $\mathrm{N}_{-} \mathrm{NH}_{3}$ foi de $22 \mathrm{mg} / \mathrm{dL}$ no líquido ruminal.

Analisando o efeito cúbico para a variável tratamento do $\mathrm{N}-\mathrm{NH}_{3}$, o ponto máximo obtido para a concentração de $\mathrm{N}_{-} \mathrm{NH}_{3}$ no líquido ruminal, foi com $28 \%$ de substituição do FS por TNF. Corroborando, desta forma, que o potencial de consumo em \%PV de MS e em g/kg $\mathrm{PV}^{0,75}$ de $27 \%$ de substituição promoveu o maior aporte proteico dietético para a flora microbiana ruminal, proporcionando a quantidade máxima de 7,03 mg N-NH$/$ /dl no líquido ruminal utilizando este nível. Portanto, o potencial máximo de consumo da TNF obtida no presente estudo, conjugado pela disponibilidade de energia existente na dieta, a produção de $\mathrm{N}-\mathrm{NH}_{3}$ está dentro da faixa de normalidade das condições ruminais.

O efeito linear para tempo observado na (Tabela 4) para o $\mathrm{N}-\mathrm{NH}_{3}$ pode ser justificado pela redução de PDR na dieta dos animais quando o FS foi sendo substituindo por TNF (Tabela 2), não proporcionando desta forma, segundo dados das médias dos tratamentos, grandes quantidades de proteína a ser fermentada e conseqüente ser observada uma menor concentração de $\mathrm{N}_{-} \mathrm{NH}_{3}$ no líquido ruminal após a alimentação dos animais.

Avaliando o efeito do metabolismo protéico 2, 6 e 8 horas após a alimentação dos animais contidos na (Tabela 4), verificou-se que a ração contendo $25 \%$ de substituição do FS por TNF, proporcionou a concentração de 17,20, 21,19, 19,06 mg NUP/ dl. Apesar da quantidade de PDR desta ração ser menor numericamente quando comparado ao da dieta isenta de nabo forrageiro, o aumento de seu consumo (Tabela 3), grau de fermentação protéica (Tabela 4) no rúmen e a digestibilidade da proteína bruta da dieta (BARBERO et al., 2007), maior fração protéica $A, B 1, K d$ (taxa de degradação) e DE (degradabilidade efetiva) da TNF quando comparado ao FS (FORTALEZA, 2007), contribuíram de maneira significativa para uma maior concentração de NUP no plasma dos animais.

Broderick, Craig e Ricker (1993), propuseram que concentrações de uréia plasmática em bovinos de corte menor que $11 \mathrm{mg} / \mathrm{dL}$, indicavam uma deficiência de PDR nas rações fornecidas, o que 
provavelmente não ocorreu neste estudo, pois de uma maneira geral os valores obtidos foram maiores que o relatado pelo autor.

Levando em consideração as médias obtidas de $\mathrm{mg}$ NUP/dl no líquido ruminal, juntamente com o efeito linear negativo para a teores de TNF, as alterações proporcionadas pela ração com 100\% de torta de nabo forrageiro, sob os parâmetros de consumo, $\mathrm{pH}$ e $\mathrm{N}-\mathrm{NH}_{3}$, foram responsáveis pelos menores valores encontrados no presente estudo. Logo, este nível de inclusão não é recomendado para se utilizar na dieta de bovinos como única fonte protéica, pois não proporcionou o consumo em níveis adequados dos nutrientes e por ter influenciado os outros parâmetros avaliados. Portanto, perante os dados analisados, o potencial de consumo da TNF em \%PV e em g/kg PV ${ }^{0,75}$ foi obtido com $27 \%$ de substituição na base protéica em relação ao FS, que por sua vez, este nível de substituição proporcionou alterações na dinâmica ruminal e sanguíneos dentro dos limites aceitáveis.

\section{Conclusões}

$\mathrm{O}$ potencial de consumo de MS em \%PV e em $\mathrm{g} / \mathrm{kg} \mathrm{PV} \mathrm{PV}^{0,75}$ da TNF foi obtido com $27 \%$ de substituição na base protéica em relação ao FS, promovendo através desta, um consumo máximo de $0,217 \mathrm{~kg} /$ animal/dia, proporcionando desta forma alterações na dinâmica ruminal e sanguíneos dentro dos limites aceitáveis.

Mais estudos são necessários para viabilizar a utilização da TNF na dieta de bovinos de corte, principalmente aquelas utilizando a TNF em dietas de animais em crescimento onde a participação do concentrado é mais pronunciada quando comparado a este experimento.

\section{Referências}

BARBERO, R. P.; FORTALEZA, A. P. S.; MASSARO JUNIOR, F. L.; JUNIOR, F. L.; BARBOSA, M. A. A. F.; SILVA, L. D. F. Suplementação de novilhas mestiças a pasto com torta de nabo forrageiro em comparação a diferentes fontes protéicas. In: REUNIÃO BRASILEIRA DE ZOOTECNIA, 45., 2008, Lavras. Anais... Lavras: UFLA, 2008. CD-ROM.

BARBERO, R. P.; SILVA, L. D. F.; MASSARO JUNIOR, F. L.; FORTALEZA, A. P. S.; .CASTRO, V. S. ALVES, K. R.; FREITAS JUNIOR, J. G. Consumo e digestibilidades totais da matéria seca, matéria orgânica e proteína bruta em bovinos de corte em respostas a níveis de torta de nabo forrageiro em substituição ao farelo de soja. In: ZOOTEC 2007, Londrina. Anais... Londrina: UEL, 2007. CD-ROM.

BERCHIELLI, T. T.; PIRES, A. V.; OLIVEIRA, S. G. Nutrição de ruminantes. Jaboticabal: Funep, 2006. 583 p.

BRODERICK, G. A.; CRAIG, W. M.; RICKER, D. B. Urea versus true protein as supplement for lactating dairy cows fed grains plus mixtures of alfafa and corn silages. Journal of Dairy Science, Champaign, v. 76, n.8, p. 2266-2274, 1993.

BURGI, R. Equipamentos para manejo e tratamento de resíduos agrícolas e agroindustriais.In: SIMPÓSIO SOBRE UTILIZAÇÃO DE SUBPRODUTOS AGROINDUSTRIAIS ERESÍDUOS DE COLHEITA NA ALIMENTAÇÃO DE RUMINANTES, 1., 1992. São Carlos. Anais... São Carlos: EMBRAPA, 1992. p. 69-82.

COELHO DA SILVA, J. F.; LEÃO, M. I. Fundamentos de nutrição dos ruminantes. Piracicaba: Livroceres, $1979.380 \mathrm{p}$.

FERREIRA, S. L.; SANTOS, A. M.; SOUZA, G. Análise por cromatografia gasosa de btex nas emissões de combustão interna alimentado com diesel e mistura diesel-biodiesel (B10). Química Nova, São Paulo, v. 31, n. 3, p. 539-545, 2008.

FORTALEZA, A. P. S. Fracionamento "in vitro" de carboidratos e proteinas e cinética da degradação "in situ” de alguns alimentos concentrados. 2007. Dissertação (Mestrado em Ciência Animal) - Universidade Estadual de Londrina, Londrina.

GABARRA, P. R. Digestibilidade de nutrientes $e$ parâmetros ruminais e sanguíneos de novilhos nelore alimentados com fontes protéicas e energéticas com diferentes degradabilidades ruminais. 2001. Dissertação (Mestrado em Agronomia) - Escola Superior de Agricultura Luiz de Queiroz, São Paulo.

HOOVER, W. H. Chemical factores involved in ruminal fiber digestion. Journal of Dairy Science, Madison, v. 69, n. 10 , p. $2755-2766,1986$.

KEARL, L. C. Nutrient requeriments of ruminants in developing countries. Logan, Utah: International Feedstuff Institute. Utah State University, 1982. 
MELLO, D. F.; FRANZOLIN, R.; FERNANDES, L. B.; ANA FRANCO, V. M.; ALVES, T. C. Avaliação do resíduo de nabo forrageiro extraído da produção de biodiesel como suplemento para bovinos de corte em pastagens. Revista Brasileira de Saúde e Produção Animal, Salvador, v. 9, n. 1, p. 45-56, 2008.

MERTENS, D. R. Regulation of forage intake. In: NATIONAL CONFERENCE ON FORAGE QUALITY. EVALUATION AND UTILIZATION, 1994. Proceedings... Lincoln: University of Nebraska. 1994. p. 450-493.

NATIONAL RESEARCH COUNCIL - NRC. Nutriente requirements of beef cattle. 7. ed. Washington: National Academic Press, 1996. 242 p.

NEIVA JUNIOR, A. P. Subprodutos agroindustriais do biodiesel na alimentação de ruminantes. Brasília: [s. n], 2007. Disponível em: <http://www.biodiesel.gov.br>. Acesso em: 05 dez. 2008.

RUSSELL, J. B.; O'CONNOR, J. D.; FOX, D. G.; VAN SOEST, P. J.; SNIFFEN, C. J. A. A net carbohydrate and protein system for evaluating cattle diets: I ruminal fermentation. Journal of Animal Science, Champaing, v. 70, n. 11, p. 3551-61. 1992.
SAS Institute. SAS/STAT user's guide. 6. ed. Version 8.2. Cary: Statistical Analysis System Institute, NC, USA, 1999-2001.

SILVA, D. J.; QUEIROZ, A. C. Análises de alimentos: métodos químicos e biológicos. 3. ed. Viçosa: UFV, 2002. $235 \mathrm{p}$.

SILVA, L. D. F.; CASTRO, V. S.; MORI, R. M. BETT, V.; VIEIRA, M. T. L.; MASSARO JUNIOR, F. L.; SANTOS, A. X.; BERAN, F. H. B.;CORRÊA, R. A.; DOMINGUES, A. R.; SALMAN, A. K. D. Degradabilidade "in situ" de silagem de cana-de-açúcar (Saccharum spp), farelo de algodão e torta de girassol em bovinos. In: REUNIÃO ANUAL DA SOCIEDADE BRASILEIRA DE ZOOTECNIA, 42., 2005, Goiânia. Anais.... Viçosa : Sociedade Brasileira de Zootecnia, 2005. CD-ROM.

SLYTER, L. L.; SATTER, L. D.; DINIUS, D. A. Effect of ruminal ammonia concentration on nitrogen utilization by steers. Journal of Animal Science, Madison, v. 48, n. 3, p. 906-912, 1979.

VIEIRA, P. F. Efeito do formaldeído na proteção de proteinas e lipídios em rações para ruminantes. 1980. Tese (Doutorado em Zootecnia) - Universidade Federal de Viçosa, Viçosa, MG. 